\title{
Growth Retardation, Colonial Changes and Nutritional Deficiency in Mycobacterium phlei Due to Lysogeny
}

\author{
By S. E. JUHASZ \\ Research Branch, Canada Department of Agriculture, \\ Vancouver, British Columbia, Canada* \\ (Accepted for publication I8 December 1967) \\ SUMMARY
}

Changes in Mycobacterium phlei due to B2h lysogeny were studied by the replica plating method. The changes could be divided into three categories: mutation to slow growth and small colony size; mutation to relative but complex nutritional requirements; and finally mutation to thiamine deficiency (thi $\left.{ }^{-}\right)$. A segregant clone obtained in the thi ${ }^{-}$mutant showed the characteristics of slow-growing small colony variants. Change in the bacterial host could be related to the type of integrated phage.

\section{INTRODUCTION}

Genetic changes in bacteria due to host-phage interaction have been repeatedly reported. Toxin production in Corynebacterium diphtheriae (Freeman, 195I ; Barksdale, 1959), altered colonial morphology in Bacillus megaterium (Ionesco, 1953), changes in the antigenic composition of Salmonella (Uetake, Nagakawa \& Akiba I955) are the best known instances of phage and lysogenic conversion.

Lysogenic conversion in Mycobacterium phlei affects colonial morphology, growth characteristics and nutritional requirements, as reported briefly by Juhasz \& Bönicke (I966) and Juhasz (I967a). It has also been found instrumental in the conversion of $M$. phlei to $M$. smegmatis (Juhasz, $1967 b$ ). In this paper the effects of lysogeny by phage B2h in $M$. phlei are described in detail.

\section{METHODS}

Bacterial strains. Mycobacterium phlei F 89 (hereafter designated F89) was obtained from Dr S. Froman, Olive View Sanatorium, Olive View, California. F89(B2h) strains $\mathrm{I}-5$ were isolated from lysogenic complexes established between $\mathrm{F} 89$ and phages $\mathrm{B} 2$ and $\mathrm{B} 2 \mathrm{~h}$, respectively. Both their isolation and purification by serial single colony transfers were described earlier (Juhasz \& Bönicke, I966; Juhasz, I967b). Since each of the five highly purified lysogenic strains showed B2h immunity and released, under certain conditions, infectious $\mathrm{B} 2 \mathrm{~h}$ particles, all of them will be referred to as $\mathrm{B} 2 \mathrm{~h}$ lysogens irrespective of whether they were infected originally with $B_{2}$ or $B_{2} h . F 89$ (B2h) strains I-3 were originally designated F89(B2h), F89(B2) and F 89(B2)"'" (Juhasz \& Bönicke, I966). The bacterial strains were maintained on Loewenstein-Jensen

* Present address: Department of Microbiology, Loyola University Stritch School of Medicine, Post Office Box 1336, Hines, Illinois, 60141, U.S.A. 
medium. Immediately before use they were transferred and grown on nutrient agar (Difco).

Phages. Phage phlei B2 (hereafter designated B2) was isolated from dung (Juhasz \& Bönicke, 1965). Phage B2h.F 89 (hereafter designated B2h) was obtained on reisolation of phage from lysogenic strain F89(B2) (Juhasz \& Bönicke, 1966). Propagation and purification of phages as well as their use in the lysogenization of strain F89 were described elsewhere (Juhasz \& Bönicke, I965; Juhasz \& Bönicke, I966).

Persistence of lysogeny was tested repeatedly during the experiments by testing for (a) the release of infectious particles able to form plaques on the susceptible strain $\mathrm{F} 89$ and $(b)$ the superinfection immunity of strains to phages $\mathrm{B} 2$ and $\mathrm{B} 2 \mathrm{~h}$.

Replica plating. Tenfold dilutions of each strain were spread over nutrient agar plates and the plate which showed 50-100 colonies was chosen as masterplate. The replica plating technique of Lederberg \& Lederberg (1952) was used to transfer the colonies to complete medium, minimal medium and minimal media supplemented with complex nutrients such as yeast extract, yeast RNA and casein hydrolysate+ tryptophan. Subsequently, minimal media were supplemented with single growth factors: vitamins, amino acids, nucleosides, nucleotides, purine and pyrimidine bases, or, if necessary, combinations thereof.

Media. Nutrient agar was used for complete medium. The minimal medium used was a modified Davis minimal medium (Lederberg, 1950); $0.5 \%$ glycerol replaced glucose as carbon source. Yeast extract was used in $0.3 \%$, casamino acids and nucleic acid derivatives in $50 \mu \mathrm{g}$. per ml. amounts. With the exception of the complete medium, media were solidified by $\mathrm{I} \cdot 5 \%(\mathrm{w} / \mathrm{v})$ purified agar. The ingredients of media and chemicals were obtained from the following manufacturers: nutrient agar, yeast extract and purified agar from Difco; amino acids, thiamine and ascorbic acid from the British Drug Houses Ltd., other vitamins and yeast RNA from Mann Research Laboratories, Inc. In addition to the latter, yeast RNA prepared by Nutritional Biochemical Corp., and Worthington Chemicals were used in special studies with the thi ${ }^{-}$mutant.

\section{RESULTS}

(i) Growth characteristics of lysogens. Three main categories could be distinguished among the investigated lysogens. (I) Slow-growing small colony variants; F 89 (B2h) strains I and 2 ; (2) strains with complex but partial nutritional requirements; F 89 (B2h) strains 3 and $4 ;(3)$ thi- mutant; F89(B2h) strain 5 .

Plate I shows the growth of these categories on replica plates after 7- to 8-day growth. Failure to grow on minimal medium distinguishes the thi- class from the other categories. The slow-growing small colony class only reach $\frac{1}{2}-\frac{1}{3}$ the size of wildtype colonies, even when grown on complete medium. The strains with complex but partial nutritional requirements only reach full size when grown on complete medium or media supplemented with yeast extract. It is obvious from Pl. I that the thiamine requirement of thi- can be replaced to a considerable extent by yeast RNA. This effect is not due to contamination of yeast RNA with thiamine, since RNA obtained from different sources, including sRNA, had a similar effect while yeast DNA had no effect. More important, the pyrimidine moiety of thiamine (2-methyl-4amino-5-hydroxymethyl pyrimidine provided by the courtesy of Merck, Sharp and Dohme of Canada Ltd., Montreal) restored full growth to the thi- mutant. 
Figure I shows the growth curves for colonies in each category as indicated by colony size on replica plates. It is clear that the initial growth rate of wild-type colonies on minimal medium is about half that on complete medium. The growth rate of the slow-growing small colony variant is about 2-4 times slower than that of the other two categories on complete medium and it produces colonies $\mathrm{I} \cdot 8-2 \cdot 4 \mathrm{~mm}$. diam. after I4 days, while colonies of the other two classes measure $4.0-5.0 \mathrm{~mm}$. diam. In addition to slow growth and small colony size this group shows other heritable changes such as decrease in pigmentation and a tendency to grow embedded in the medium in the form of smooth colonies. In contrast to the thiamine-requiring mutant the other categories can grow to varying degrees on minimal medium.

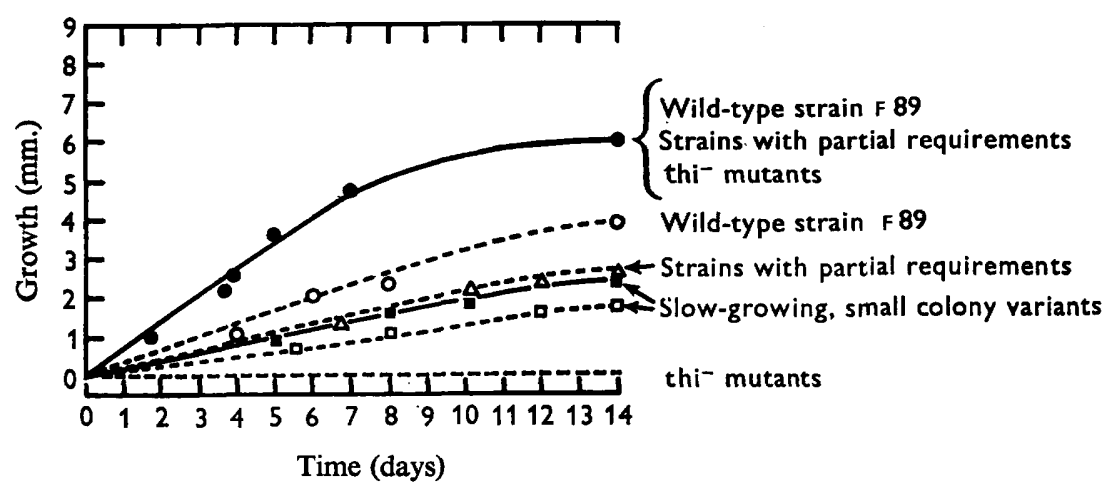

Fig. I. Differences in growth rate between Mycobacterium phlei $\mathrm{F} 89$ and its lysogenic derivatives as indicated by colony size on complete and minimal media. -, Complete medium; --- , minimal medium.

Table I. Changes in Mycobacterium phlei F89 relative to the type of integrated phage genome

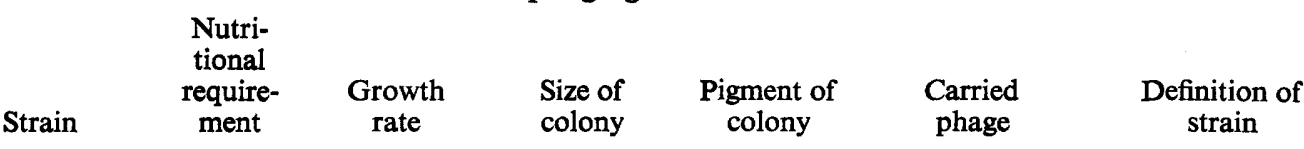

\begin{tabular}{|c|c|c|c|c|c|c|}
\hline $\left.\begin{array}{l}\text { F89(B2h) no. I } \\
\text { F } 89 \text { (B2h) no. } 2\end{array}\right\}$ & None & $\begin{array}{l}\text { Slow (2- to } \\
4 \text {-fold } \\
\text { decrease) }\end{array}$ & $\begin{array}{l}\text { Small } \\
(\mathrm{I} \cdot 8- \\
2 \cdot 4 \mathrm{~mm} .)\end{array}$ & $\begin{array}{l}\text { Pale yellow to } \\
\text { colourless }\end{array}$ & Incomplete B2h & $\left\{\begin{array}{l}\text { Slow-growing, } \\
\text { small colony } \\
\text { variant. } \\
\text { Lysogenic }\end{array}\right.$ \\
\hline $\left.\begin{array}{l}\text { F89(B2h) no. } 3 \\
\text { F89(B2h) no. } 4\end{array}\right\}$ & Partial & $\begin{array}{l}\text { Slightly } \\
\text { retarded }\end{array}$ & As wild type & $\begin{array}{l}\text { Pale yellow } \\
\text { (whitish) }\end{array}$ & B2h & $\left\{\begin{array}{l}\text { Partial require- } \\
\text { ment. } \\
\text { Lysogenic }\end{array}\right.$ \\
\hline F 89 (B2h) no. 5 & Thiamine & As wild type & As wild type & As wild type & Defective B2h? & $\begin{array}{l}\text { Thiamine-less. } \\
\text { Defective } \\
\text { lysogen? }\end{array}$ \\
\hline Wild F 89 & None & Fast & 3-5 mm. & Yellow & None & $\begin{array}{l}\text { Prototrophic. } \\
\text { Phage sensitive }\end{array}$ \\
\hline
\end{tabular}

The number of mutant classes among B2h lysogens may have been limited by the number of randomly selected strains, therefore $\mathrm{F} 89$ was freshly infected with $\mathrm{B} 2 \mathrm{~h}$ at a multiplicity of 3 and the effect of phage was studied before and after purification of lysogenic clones. From 23 single colonies examined 18 became stably lysogenic; 15 of 
these were slow-growing small colony variants and three showed complex partial nutritional requirements. thi- mutants were not recovered in this experiment.

Among the rare segregants encountered from these groups, one in the thi- category revealed the characteristics of the slow-growing small colony variant.

(ii) Phage carried by different categories of B2h lysogens. A correlation has been found between changes in F 89 host and the type of integrated B2h genome (Table 1 ). Complete B2h genome could be demonstrated only in strains with complex but partial nutritional requirements. The slow-growing small colony variants harboured a B2h genome, the $h$ region of which could not be recovered; none the less they produced infectious particles and carried B2h immunity. Finally, no infectious particles could be demonstrated in the thi- category; however, $\mathrm{F} 89(\mathrm{~B} 2 \mathrm{~h})$ strain 5 was immune to superinfection by phage $\mathrm{B} 2 \mathrm{~h}$.

\section{DISCUSSION}

The experiments reported here were carried out with purified lysogens in order to analyse hereditary changes in Mycobacterium phlei F89 following B2h infection. The results obtained when $\mathrm{F} 89$ was relysogenized with $\mathrm{B} 2 \mathrm{~h}$ indicated, however, that the original 5 strains of this study were not a selected sample but probably rather represented the whole spectrum of change in $\mathrm{F} 89$ host following B2h integration.

The most characteristic type of change associated with B2h lysogeny is slow-growing small colony variation. Such changes were never observed in control F89 cultures although phenotypic fluctuation in colony size occurred frequently. Attempts to isolate small colony mutants from wild type failed since subsequent transfers of small colonies yielded repeatedly large colonies along with small ones. In addition, while small and large wild-type colonies differed only in size as a result of random fluctuation, the colony size of slow-growing small colony variants was heritable together with other stable hereditary changes, such as considerable loss of pigmentation and a novel and strong tendency to grow embedded in the medium.

The conditions under which quantitative conversion to slow growth and small colony size occurred were earlier established. At a multiplicity of $\mathrm{I}, \mathrm{a} 5 \times 10^{-5}$ fraction of the F89 population survived B2h.F 89 infection, more than half of which became stably lysogenic as well as slow-growing small colony variants (Juhasz, $1967 b$ ). On the other hand, from among several hundred colonies of similarly diluted control F 89 suspensions none showed these characteristic hereditary changes.

In contrast to the former type of change the conditions for quantitative conversion to either absolute or partial nutritional requirements have not yet been sufficiently studied. Conversion to partial nutritional requirements upon B2h lysogeny occurred frequently; but conversion to thiamine deficiency was not observed beyond the already available thi- strain. This particular strain was immune to superinfection by B2h. Despite lack of any other evidence for the presence of a defective prophage at the time when thiamine deficiency was detected, mutation to phage resistance was not seriously considered for the following reasons. (I) F 89 (B2h) strain 5 was obtained upon lysogenization of $\mathrm{F} 89$ with $\mathrm{B} 2 \mathrm{~h}$, (2) this strain was found to release infectious $\mathrm{B} 2 \mathrm{~h}$ particles in studies prior to the present one. Therefore it was hypothesized that thiamine deficiency resulted from additional changes in $\mathrm{F} 89$ (B2h) host. Persistent diploidy over the thi locus of $F 89$ and a reversible exchange between this and the immunity region of $B_{2} h$ could explain defective lysogeny, thiamine deficiency and segregation to slow-growing small colony variants. Nevertheless, so long as 

Journal of General Microbiology, Vol. 52, No. 2

Plate I

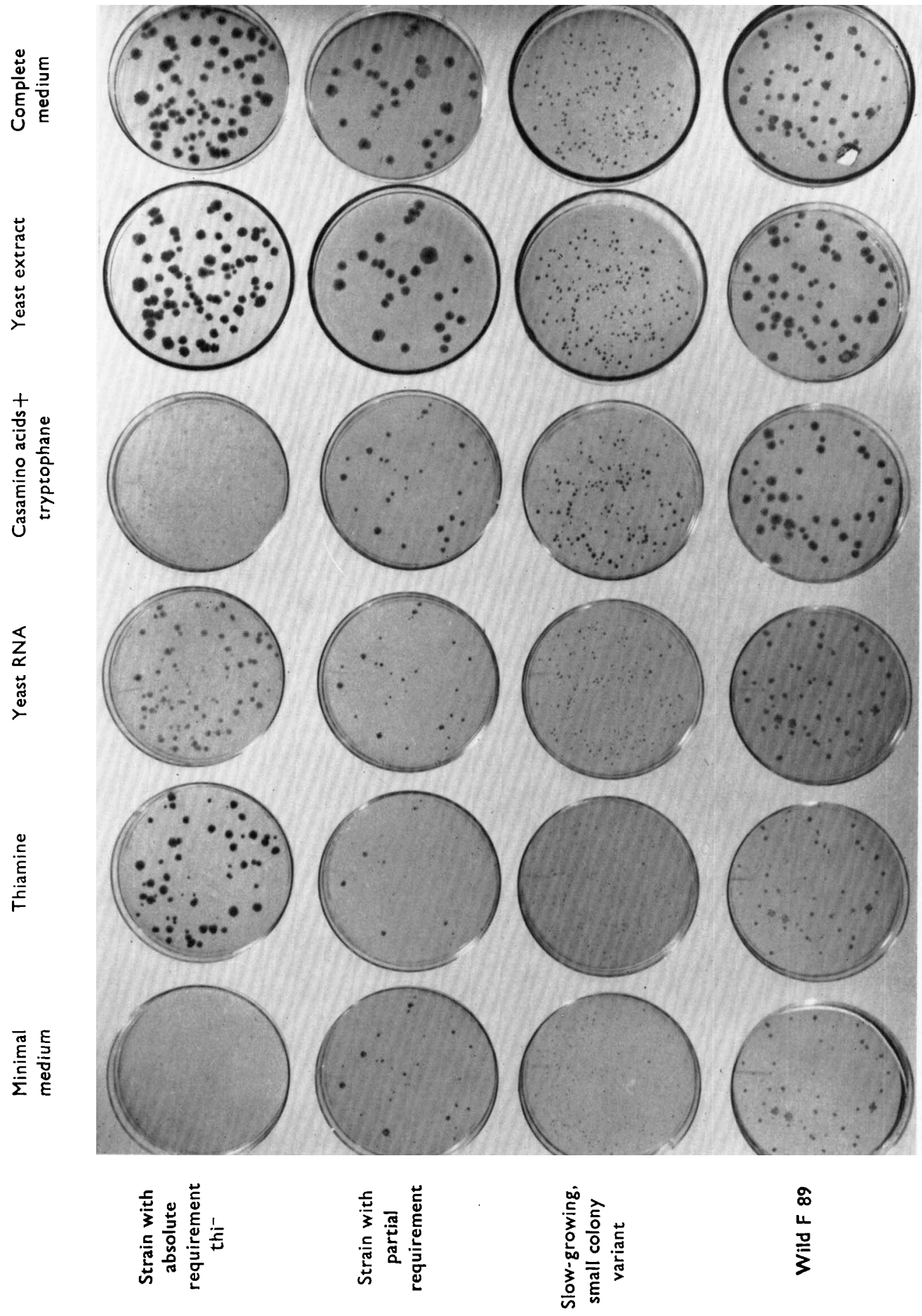


quantitative recovery of thi- mutants cannot be achieved, it will be impossible to rule out a spontaneous mutational origin for thiamine deficiency in this strain.

Phage-induced mutation to auxotrophy was earlier reported in Escherichia coli (Taylor, 1963). The circumstances under which MU I and B2h were isolated as well as their respective role in producing mutants bore much resemblance. However, in contrast to B2h, Taylor's mutator phage elicited a wide range of mutant classes in E. coli. Henceforth his conclusion: 'The overall effect of MU I on bacteria is superficially indistinguishable from that of a mutagen.' On the other hand, the following observations indicate the possibility of a fixed chromosomal location of B2h on the $\mathrm{F} 89$ chromosome: (a) the consistently small number of mutant classes; $(b)$ the link between the thi ${ }^{-}$mutant and the slow-growing small colony variants; $(c)$ the correlation between the type (length) of integrated phage and the nature of change in the bacterial host.

Finally, it must be emphasized that it was noticed with great interest that yeast RNA could replace thiamine to a considerable degree in the thi ${ }^{-}$group. Results of a study in progress on the biosynthesis of the pyrimidine moiety of thiamine will be published elsewhere.

This work was carried out at the Research Station, Canada Department of Agriculture, Vancouver, thanks to the generous hospitality of Dr. M. Weintraub, Chief, Section of Virus Chemistry and Physiology. Continuous interest and innumerable stimulating discussions with Dr. H. Ragetli of the Research Station are gratefully acknowledged. The experiments were carried out with the able assistance of Mr. N. Cvorkov.

\section{REFERENCES}

BARKSDALE, L. (1959). Lysogenic conversions in bacteria. Bact. Rev. 23, 202.

Freeman, V. J. (I95I). Studies on the virulence of bacteriophage-infected strains of Corynebacterium diphtheriae. J. Bact. 6r, 675.

IonesCo, H. (1953). Sur une propriété de B. megaterium liée á la présence d'un bacteriophage. C. $r$. Séanc. Soc. Biol. 237 , 1794.

JUHASZ, S. E. \& BöNICKE, R. (I965). Possible classification of rapidly growing mycobacteria on the basis of their phage susceptibility. Can. J. Microbiol. xI, 235.

JuHAsZ, S. E. \& BöNICKE, R. (1966). Reciprocal genetic changes in mycobacterial host-virus systems: Effect of lysogeny on the phage. Nature, Lond. 210, 1185.

JuHAsz, S. E. (1967a). Growth retardation, colony changes and auxotrophy in Mycobacterium phlei due to lysogeny. Bact. Proc. p. 145.

JuHASz, S. E. (1967b). Reciprocal in toto conversion of Mycobacterium phlei $\rightleftarrows$ Mycobacterium smegmatis by mediation of an intermediate hybrid genome: B2h. Nature, Lond. 214, 518.

LEDERBERG, J. (1950). Isolation and characterization of biochemical mutants of bacteria. Meth. med. Res. 3, 5 .

LEDERBERG, J. \& LEDERBERG, E. M. (1952). Replica plating and indirect selection of bacterial mutants. J. Bact. 63, 399.

TAYLOR, A.L.(1963). Bacteriophage-induced mutation in Escherichia coli.Proc.natn. Acad. Sci., U.S.A. 50, 1043 .

Uetake, H. T., Nagakawa, T. \& Akrba, T. (1955). The relationship of bacteriophage to antigenic changes in group E salmonellas. J. Bact. 69, 57I.

\section{EXPLANATION OF PLATE}

Plate I

Comparison of growth of wild Mycobacterium phlei $\mathbf{F} 89$ and its lysogenic derivatives on replica plates. Incubated at $37^{\circ}$ for $7-8$ days. $\times 0 \cdot 28$. 